\title{
Effect of Home Exercise with Taping on the Pain and Functional Disability in Patients with Carpal Tunnel Syndrome
}

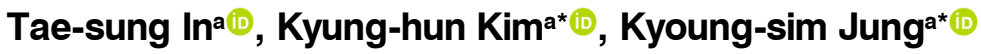 \\ aDepartment of Physical Therapy, Gimcheon University, Gyeongsangbuk-do, Republic of Korea \\ *These authors contributed equally to this work
}

\begin{abstract}
Objective: Carpal tunnel syndrome is one of the most common upper extremity compressive nerve disorders in modern people.Various conservative treatments such as taping, exercise, and electrotherapy have been applied to carpal tunnel syndrome and their effectiveness has been proven. This study aims to determine whether home exercise combined with taping is effective for pain and functional disability in patients with carpal tunnel syndrome.
\end{abstract}

Design: Randomized controlled study

Methods: 21 patients were recruited and were randomly divided into HEx $+\mathrm{T}$ (Home exercise + taping) group $(\mathrm{n}=10)$ and HEx (Home exercise) group $(\mathrm{n}=11)$. All participants performed Home exercise(tendon and neural gliding exercise) 5 times a week for 6 weeks. Additionally, subject in the HEx group, taping was applied over the wrist and forearm during the training period. Wrist pain was measured by VAS (Visual Analogue Scale). Functional disability was measured using a BCTSQ(The Boston Carpal Tunnel Syndrome Questionnaire).

Results: Both the HEx + T group and the HEx group showed a significant improvement in wrist pain $(p<0.05)$, and the HEx $+\mathrm{T}$ group showed a more significant decrease in pain than the HEx group $(\mathrm{p}<0.05)$. There was a significant improvement in both groups in functional disability $(\mathrm{p}<0.05)$, and the HEX $+\mathrm{T}$ group showed more improvement than the HEX group $(\mathrm{p}<0.05)$.

Conclusions: This study suggests that home exercise combined with taping is effective for pain and functional disability in patients with carpal tunnel syndrome.

Key Words: Carpal Tunnel Syndrome, Disability, Pain, Neural Gliding Exercise, Taping

서론

최근 현대사회는 장시간 같은 동작을 반복하는 컴퓨터 및 스마트폰을 사용하는 사람이 증가하고 있다[1]. 반복적 인 동작은 근육 및 신경을 손상시켜 허리, 목, 어깨, 팔, 손목 등 다양한 부위에 기능장애를 발생시킨다[2]. 손목터 널증후군은 상지에서 가장 흔한 압박성 신경성 질환 중 하나로, 통증 및 정중신경 지배 영역의 감각 이상을 야기 한다[3]. 발생빈도는 100,000 명당 99 명에서 발병하는 비 교적 흔한 질병으로 남녀 모두에게 발생하지만 특히, 40 60세 사이에서 가장 흔하게 발생한다[4]. 손목터널증 후군의 정확한 원인은 밝혀지지 않았지만 손과 손목의 반 복적인 사용, 노화, 비만, 임신, 당뇨, 신장질환, 외상, 골
관절염, 갑상선 질환 등이 위험요인으로 알려져 있다[5]. 임상적 증상으로는 정중신경이 분포하는 영역에 저림, 통 증, 감각저하, 손가락움직임의 둔화 등 매우 다양하게 발 생한다[6].

손목터널증후군의 치료방법으로는 스프린트를 사용하 여 손목을 고정하거나 초음파, 침술, 도수치료, 코르티코 스테로이드의 국소 주입[7], 신경 활주 운동[8]과 저출력 레이저가 증상 완화에 효과적이라는 연구들이 보고되고 있다[9]. 최근에는 손목터널증후군 환자를 대상으로 테이 핑 치료에 대한 효과가 많이 보고되고 있다[10,11]. 테이 핑의 특성인 신축성으로 인해 통증 완화 및 근력 증가에 영항을 미친다고 하였다[12]. 또한, 손목 공간을 확장하기 위한 테이핑 기법을 적용하여 신경전도속도가 대조군에

Received: Aug 28, 2021 Revised: Sep 15, 2021 Accepted: Sep 23, 2021

Corresponding author: Kyoung-sim Jung(ORCID https://orcid.org/0000-0002-3684-0592)

Department of Physical Therapy, Gimcheon University 214, Daehak-ro, Gimcheon-si, Gyeongsangbuk-do 39528, Republic of Korea.

Tel: + 82-54-420-4068 Fax: + 82-54-420-4467 E-mail: jkspt@hanmail.net

This is an Open-Access article distributed under the terms of the Creative Commons Attribution Non-Commercial License (http://creativecommons.org/licenses/ by-nc/4.0) which permits unrestricted non-commercial use, distribution, and reproduction in any medium, provided the original work is properly cited.

Copyright $(2021$ Korean Academy of Physical Therapy Rehabilitation Science 
비해 유의하게 개선되었다고 보고하였다[10].

그러나 손목터널증후군 환자를 대상으로 운동과 테이 핑의 병행 효과를 확인한 연구가 미비한 실정이다. 따라 서 본 연구의 목적은 테이핑을 병행한 가정운동프로그램 이 손목터널증후군 환자의 통증과 기능에 미치는 효과를 파악하고자 한다.

\section{연구방법}

\section{연구대상}

본 연구는 경기도에 거주중인 손목터널증후군 환자 21 명을 대상을 실시하였다. 2020년 11월부터 12월까지 광 고포스터를 통해 모집하였다. 대상자 선정기준은 정형외 과 의사에 의해 손목터널증후군으로 진단받았으며, 시각 적 사상척도가 5점 이상인 자를 대상으로 하였다. 이전에 손목터널증후군 수술을 받았거나 흥곽출구증후군, 경추의 신경근병증 또는 말초신경염, 손이나 손목의 외상이 있는 자는 제외하였다.

\section{연구절차}

Pilot test(6명 대상) 결과를 토대로 $\mathrm{G}^{*}$ power3.1.9.2 프로그램을 사용하여 샘플사이즈를 계산한 결과 총 18 명 이 나왔다 $\alpha$ 오류: 0.05 , 힘: 0.8 , 효과크기: 0.86). 탈락자 를 감안하여 22명을 대상자로 선정하였고, 선정편견을 최 소화하기 위하여 배정번호가 담긴 밀봉된 봉투를 사용하 여 무작위로 Home exercise+Taping $(\mathrm{HEx}+\mathrm{T}, \mathrm{n}=11)$ 군과 Home exercise(HEx, $\mathrm{n}=11)$ 군으로 나누었다. 훈련
중 $\mathrm{HEx}+\mathrm{T}$ 군에서 테이핑으로 인한 피부발적으로 한명 이 탈락하였으며, 총 21 명이 사후 평가에 참여하였다. 훈련을 적용하기 전과 6주 후에 시각적 사상척도 (Visual Analogue Scale, VAS)와 기능장애(The Boston Carpal Tunnel Syndrome Questionnaire, BCTSQ)를 측정하 였다.

\section{중재방법}

가정 운동 프로그램은 힘줄과 신경의 활주운동으로 구 성되었으며 운동별로 각 10 회씩 3 세트를 주5회 6주간 실 시 하였다. 굽힘근 힘줄 활주 운동은 펼친 손, 갈고리 그 립, 완전 주먹 쥐기, 선반 모양의 손, 일자 주먹 쥐기의 5 가지 자세에서 실시되었으며, 자세별로 5 초씩 유지하게 하였다. 정중신경 활주운동은 아래팔 뒤침, 손목을 폄시킨 상태로 엄지손가락을 벌림 시켜 반대쪽 손을 사용하여 바 깥쪽으로 늘리도록 하였다. 훈련 시작 전 3년 이상의 숙 련된 치료사가 운동방법을 교육하였으며, 운동은 자가로 수행하게 하였다[Fig 1]. 환자는 체크리스트에 운동 수행 여부를 체크하였다. $\mathrm{HEx}+\mathrm{T}$ 군은 추가적으로 테이핑을 실 시하였다. 훈련기간 동안 테이핑을 계속 부착하였고 테이 프는 3 일에 한번 교체되었다. 테이핑은 $\mathrm{Y}$ 자형태의 너비 5 $\mathrm{cm}$, 길이 $20-25 \mathrm{~cm}$ 의 키네지오 테이프를 사용하여 손목 을 최대한 폄시킨 상태에서 아래팔중간에서 시작하여 엄 지와 새끼손가락 바닥면에 부착하였다. 길이 $10 \mathrm{~cm}$ 의 테 이프를 손목의 노측에서 시작하여 자측까지 감아주었다. 마지막으로 $10 \mathrm{~cm}$ 의 테이프를 손목터널위에 세로로 부착 하였다[Fig 2][11].

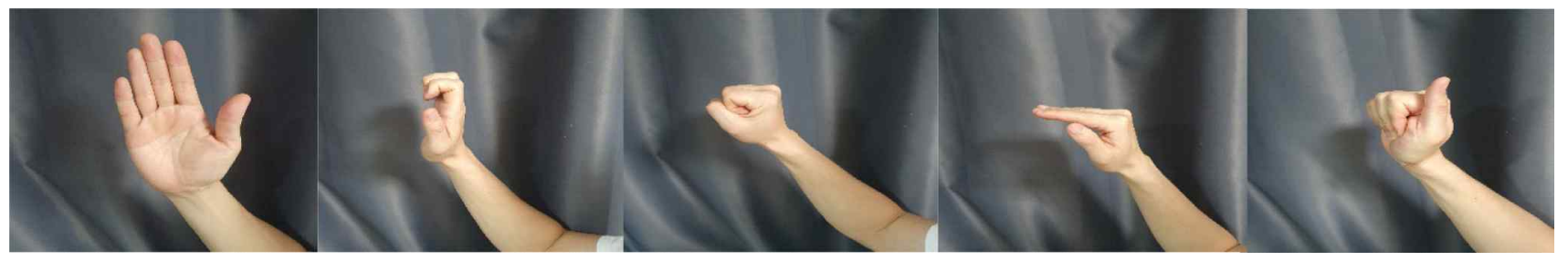

Figure 1-A. Flexor tendon gliding exercise(flat, hook, punch, table-top, flat-punch)

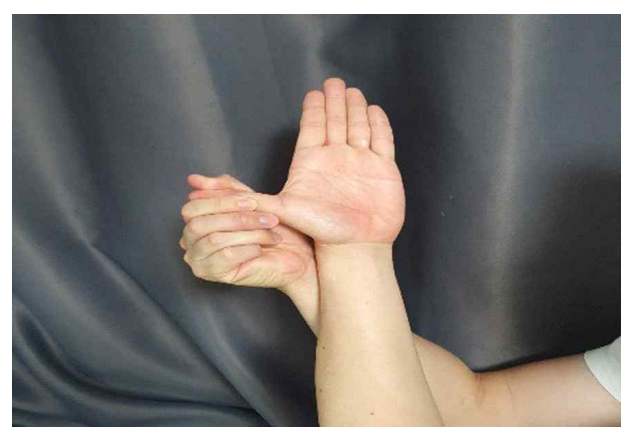

Figure 1-B. Median nerve gliding exercise

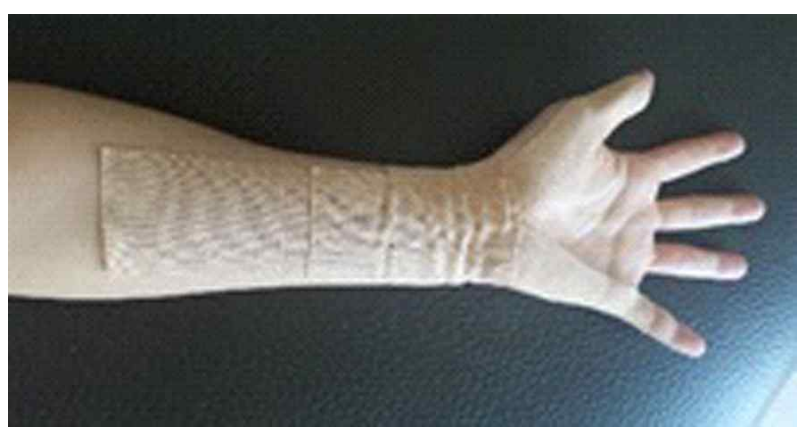

Figure 2. Taping therapy 


\section{측정방법 및 도구}

\section{통증검사}

통증의 변화는 시각적 사상척도를 이용하여 측정하였 다. 통증 강도에 따라 통증이 매우 심한 상태는 10 점, 통 증이 없는 상태는 0 점으로 체크할 수 있다. 검사 재검사 신뢰도는 $\mathrm{r}=0.96$ 이다[13].

\section{보스턴 손목터널증후군 척도}

보스턴 손목터널증후군 척도는 보스턴 증상 중증도척 도(Boston Symptom Severity Scale, BSSS) 11문항과 보스턴 기능적 수행능력 척도(Boston Functional Capacity Scale, BFCS) 8 문항으로 구성되어 있는 자가 설문척도이 다. 총19개 문항으로 구성되었으며, 총점을 문항수로 나누 어 계산한다. 각 문항은 무증상인 경우 1 점, 심한 경우 5 점이 부여되며, 점수가 높을수록 증상 및 기능장애가 심 한 것을 의미한다. 검사-재검사 신뢰도가 $\mathrm{ICC}=0.93$ 매우 높은 것으로 보고되고 있다[14].

\section{자료분석}

모든 통계 분석은 SPSS 프로그램(Version 15.0, IBM Corp, USA)을 이용하였으며, Shapiro-Wilk 검정 방법을
통해 변수들의 정규성 검정을 시행하였다. 집단 간 차이 는 Mann Whitney U-test, 집단내의 비교는 Wilcoxon signed rank test를 사용하였다. 범주형 변수의 비교를 위 해 $\mathrm{X}^{2}$-검정을 사용하였다. 모든 자료의 통계적 유의 수준 은 0.05 이하이다.

\section{연구결과}

\section{연구대상자의 일반적인 특성}

본 연구에는 손목 통증 환자 21 명이 사후검사를 완료 하였고, 일반적인 특성은 <Table $1>$ 과 같다. 집단 간의 baseline에는 유의한 차이가 없었다<Table 1>.

\section{두 군에서 중재 전과 후의 통증에 미치는 차이}

통증 점수에 있어 두 집단 모두 훈련 전 - 후 유의한 변 화가 있었으며 $(\mathrm{p}<0.05)$, 훈련 전·후 변화량에 있어서는 $\mathrm{HEx}+\mathrm{T}$ 군이 $\mathrm{HEx}$ 군보다 유의한 개선효과가 있었다 $(\mathrm{p}<0.05) .<$ Table $2>$ 와 같다.

\section{두 군에서 중재 전과 후의 기능 장애에 미치는 차이}

기능장애 점수에 있어 두 집단 모두 훈련 전·후 유의 한 변화가 있었으며 $(\mathrm{p}<0.05)$, 훈련 전·후 변화량에 있어

Table 1. General Characteristics of Participants

$(\mathrm{n}=21)$

\begin{tabular}{llll}
\hline & HEx + T group $(\mathbf{n}=\mathbf{1 0})$ & HEx group $(\mathbf{n}=\mathbf{1 1})$ & $\mathbf{p}$ \\
\hline Gender $($ Male/Female $)$ & $3 / 7$ & $4 / 7$ & $0.56^{\mathrm{b}}$ \\
Age $($ years $)$ & $38.9 \pm 5.7 \mathrm{a}$ & $42.6 \pm 6.4$ & $0.43^{\mathrm{c}}$ \\
Height $(\mathrm{cm})$ & $165.7 \pm 7.6$ & $163.5 \pm 8.4$ & $0.51^{\mathrm{c}}$ \\
Weight $(\mathrm{kg})$ & $63.6 \pm 13.4$ & $61.4 \pm 10.9$ & $0.24^{\mathrm{c}}$ \\
\hline
\end{tabular}

a. Values are expressed as mean \pm standard deviation., b. Chi-square test, c. Mann-Whitney U test. HEx + T group: Home exercise + Taping group, HEx group: Home exercise group.

Table 2. Comparison of pain and functional capacity between two groups before and after intervention

$(\mathrm{n}=21)$

\begin{tabular}{lllll}
\hline Test & Group & VAS & BSSS & BFCS \\
\hline \multirow{2}{*}{ Pre } & HEx + T group & $6.6(1.4)$ & $2.4(0.7)$ & $2.2(1.1)$ \\
& HEx group & $6.3(1.5)$ & $2.1(1.0)$ & $2.0(0.9)$ \\
\hline \multirow{2}{*}{ Post } & HEx + T group & $3.2(1.7)$ & $1.5(1.3)$ & \\
& HEx group & $4.4(1.1)$ & $1.7(0.6)$ & \\
\hline \multirow{2}{*}{ Change } & HEx + T group & $-3.4(0.9)^{* *}$ & $-0.9(0.8)^{* \#}$ & $-0.6(0.9)^{* \#}$ \\
& HEx group & $-1.9(0.7)^{*}$ & $-0.4(0.5)^{*}$ & $-0.3(0.6)^{*}$ \\
\hline
\end{tabular}

Values are expressed as mean \pm standard deviation $(\mathrm{SD})$.

${ }^{*}$ Significant differences between pre and posttest $(\mathrm{p}<0.05){ }^{\#}$ Significant differences between the group $(\mathrm{p}<0.05)$. HEx $+\mathrm{T}$ group: Home exercise + Taping group, HEx group: Home exercise group, VAS: Visual Analogue Scale, BSSS: Boston Symptom Severity Scale, BFCS: Boston Functional Capacity Scale 
서는 $\mathrm{HEx}+\mathrm{T}$ 군이 $\mathrm{HEx}$ 군보다 유의한 개선효과가 있었다 $(\mathrm{p}<0.05) .<$ Table $2>$ 와 같다.

\section{고찰}

본 연구는 6 주간 테이핑을 병행한 가정운동프로그램이 손목터널증후군 환자의 통증에 미치는 효과를 알아보았 다. 그 결과, 두 군 모두 통증이 유의하게 개선되었으나 $\mathrm{HEx}+\mathrm{T}$ 군이 HEx군에 비해 통증감소에서 유의한 효과를 나타내었다. 신경과 힘줄 활주 운동의 효과와 관련하여 손목터널증후군의 특수한 병인을 인식하는 것은 이러한 운동의 실제 효능을 결정하는데 중요하다. 정중신경의 기 계적 압박으로 인해 다양한 증상을 나타내는 손목터널증 후군의 경우 이러한 운동의 이점을 볼 가능성이 더 높다 [15]. 신경과 힘줄활주 운동은 손목과 손의 말단부위에 산 소가 풍부한 혈액을 전달하게 함으로써 허혈성 통증을 완 화시킬수 있다고 하였다[16]. 본 연구에서는 두 군 모두 신경과 힘줄활주 운동을 실시하였지만, $\mathrm{HEx}+\mathrm{T}$ 군에서 더 유의한 개선효과가 나타난 것은 테이핑으로 인한 추가적 인 통증완화 효과때문이라고 생각한다. 손목터널증후군 환자의 테이핑 치료의 목적은 피부와 연부조직을 들어올 림으로써 압박을 감소하고, 근막위치를 재배열하고, 밴드 적용부위에 고유수용자극을 제공하고, 림프배액에 따라 부종을 감소시키는 것이다[17,18]. 또한 염증부위에 적용 했을 때 혈액순환을 증가시켜 화학수용체의 자극을 감소 시킬뿐 아니라 기계수용체의 자극에 따라 관문조절설에 의해 진통효과를 제공하게 된다[11].

본 연구에서는 훈련 후 기능장애에 대해서도 측정하였 다. 관절가동술에 관한 체계적 고찰연구에서 신경과 힘줄 활주운동은 손목 보조기와 동일한 치료효과를 가진다고 보고하였으며, 방법에 따라 정도는 다르지만 신경활동의 변화를 야기하였다고 보고하였다[19]. Keskin 등[20]의 연구에서 손목터널증후군 환자를 대상으로 신경과 힘줄운 동을 실시하여 보스턴손목터널증후군 척도에서 증상 중증 도 척도에서는 증상이 심한 그룹(평균, 증상 중증도: $2.8 \pm 0.9$, 기능적 수행능력: $2.5 \pm 1.1$ )의 경우 증상 중증도와 기능적 수행능력에서 각각 1.1 과 0.8 점이 감소하며, 유의한 개선 을 나타내었고, 증상이 가벼운 그룹(평균, 증상 중증도: $2.0 \pm 0.7$ 기능적 수행능력: $2.0 \pm 1.0$ )에서는 유의한 개선이 없었다고 보고하였다. 본 연구의 대상자들은 훈련 전 보 스턴 손목터널증후군 척도의 점수가 선행연구에서 증상이 심한 그룹과 비슷한 수준을 나타내었으며, 두 그룹 모두 신경과 힘줄운동을 적용하여 기능개선에서 유의한 개선을 보였다. 또한 $\mathrm{HEx}+\mathrm{T}$ 군이 증상 중증도와 기능적 수행능 력에서 각각 0.9 점과 0.4 점이 감소되어 $\mathrm{HEx}$ 군보다 더 유 의한 개선을 나타내었다. 이러한 결과가 나타난 것은 손
목터널증후군 환자를 위한 테이핑 적용방법이 통증 및 신 경 기능을 개선하였기 때문에 신경과 힘줄활주운동의 효 과를 더욱 강화했을 것이라고 생각된다. Aktük 등[20]의 연구에서는 테이핑과 운동, 보조기와 운동의 효과를 비교 하였을 때 테이핑과 운동의 병행이 신경생리학적 변화와 보스톤 손목터널증후군 척도 등에서 더 유의한 개선효과 를 나타냈다고 하였다. 따라서 본 연구 결과를 토대로 테 이핑이 신경과 힘줄활주 운동의 효과를 강화한다는 사실 을 확인하였다.

본 연구는 손목터널증후군 환자를 대상으로 테이핑을 병행한 가정프로그램 운동이 통증 및 기능장애 미치는 영 향을 알아보았다. 하지만 대상자 수가 적어 본 연구결과 로 치료효과를 일반화하기 어려우며, 손목의 근활성도를 포함하여 다양한 방법으로 기능개선 효과를 확인할 필요 가 있다. 또한 훈련 종료 후에도 치료 효과가 지속 되는지 추적 관찰할 필요가 있겠다.

\section{결론}

본 연구는 손목터널증후군 환자를 대상으로 6 주간 테 이핑을 병행한 가정운동 프로그램이 통증 및 기능개선 미 치는 효과를 연구하였으며, 테이핑을 병행한 가정운동프 로그램이 테이핑만 적용하였을 때보다 통증 및 기능 개선 에 효과적임을 증명하였다. 본 연구결과를 토대로 손목터 널증후군 환자의 통증 및 기능 개선을 위한 운동과 테이 핑의 병행요법을 제안하였, 이러한 훈련 방법은 임상과 가정에서 저렴한 비용으로 손쉽게 적용할 수 있을 것이라 생각된다.

\section{감사의 글}

This work was supported by NRF(National Research Foundation of Korea) Grant funded by the Korean Government(2021R1F1A1063056)

\section{이해충돌}

본 연구의 저자들은 연구, 저작권, 및 출판과 관련하여 잠재적인 이해충돌이 없음을 선언합니다.

\section{참고문헌}

1. Wang, L. Guiding Treatment for Carpal Tunnel Syndrome. [Review]. Phys Med Rehabil Clin N Am. 2018;29: 751-760 
2. 김규상, 박정근 \&김대성. 직업성 근골격계질환의 발생 현황과 특성. 대한인간공학회지. 2010;29:405-422.

3. LeBlanc KE. \& Cestia W. Carpal tunnel syndrome. Am Fam 422 Physician. 2011;83:952-8.

4. Von Shroeder H.P, Botte M.J. Carpal tunnel syndrome. Hand Clin. 1996;12:643-655.

5. Stevens JC \& Beard CM. O'fallon WM, Kurland LT. Conditionsassociated with carpal tunnel syndrome. Mayo Clin Proc. 1992; 67: 541-8.

6. Seo C. W \& Kim C. S. Evaluation of nerve conduction study result in carpal tunnel syndrome before and after operation in eastern area of Jeonnam. KAIS. 2012;13:5305-5310.

7. Piazzini DB, Aprile I, Ferrara PE, Bertolini C, Tonali P \& Maggi L, et al. A systematic review of conservative treatment of carpal tunnel syndrome. Clin Rehabil. 2007;21:299-314.

8. Keskin $\mathrm{Y}$, Kilic $\mathrm{G} \&$ Taspinar $\mathrm{O}$, et al. Effectiveness of home exercise in pregnant women with carpal tunnel syndrome: Randomized Control Trial. J Pak Med Assoc. 2020;70:202-207.

9. Güner A, Atlan L \& Aksoy MK. The effectiveness of the low-power laser and kinesiotaping in the treatment of carpal tunnel syndrome, a pilot study. Rheumatol Int. 2018;38:895-904.

10. Park Y.D, Park Y.J \& Park S.S. Effects of taping therapy for carpal space expansion on electrophysiological change in patients with carpal tunnel syndrome. J Exerc Rehabil. 2017; 13:359-362.

11. Akgol G, Elbasti MS, Gulkesen A, Alkan G, Kaya A, Ulusoy H. Comparison of low power laser and kinesio taping for the treatment of carpal tunnel syndrome: A prospective randomized study. J Back Musculoskelet Rehabil. 2021;34:545-553.

12. Kase K, Wallis $\mathrm{J} \&$ Kase $\mathrm{T}$ (Ed.). Clinical therapeutic applications ofthe kinesio taping method, tokyo, Ken IkaiCo. Ltd. 2013.

13. Sindhu B.S. Shechtman O. \& Tuckey L. Validity, reliability, and responsiveness of a digital version of the visual analog scale. Journal of Hand Therapy. 2011;24:356-63.

14. Park D.J. Kang J.H. Lee J.W. Lee K.E. Wen L et al. Cross-cultural adaptation of the Korean version of the Boston carpal tunnel questionnaire: its clinical evaluation in patients with carpal tunnel syndrome following local corticosteroid injection. $\mathrm{J}$
Korean Med Sci. 2013 Jul;28(7):1095-1099.

15. Halseth T, McChesney J.W, DeBeliso M, Vaughn R \& Lien J. The effects of kinesio taping on proprioception of the ankle. Journal of Sports Science and Medicine. 2004;3:1-7.

16. Heebner ML, Roddey TS. The effects of neural mobilization inaddition to standard care in persons with carpal tunnel syndromefrom a community hospital. J Hand Ther. 2008; 21:229-40.

17. Bicici S, Karatas N, Baltaci G. Effect of athletic taping and kinesio taping on measurements of functional performance in basketball players with chronic inversion ankle sprains. Int J Sports Phys Ther. 2012;7:154-66.

18. Williams S, Whatman C, Hume PA, Sheerin K. Kinesio taping in treatment and prevention of sports injuries: a meta-analysis of the evidence for its effectiveness. Sports Med. 2012;42:153-64.

17. Akgol G, Elbasti MS, Gulkesen A, Alkan G, Kaya A, Ulusoy H. Comparison of low power laser and kinesio taping for the treatment of carpal tunnel syndrome: A prospective randomized study. J Back Musculoskelet Rehabil . 2021;34:545-553.

18. Lim YH, Chee DY, Girdler S, Lee HC. Median nerve mobilization techniques in the treatment of carpal tunnel syndrome: A systematic review. J Hand Ther. 2017;30:397-406.

19. Keskin Y, Kilic G, Taspinar O, Posul SO, Halac G, Eren F, Erol E, Urkmez B, Aydin T. Effectiveness of home exercise in pregnant women with carpal tunnel syndrome: Randomized Control Trial. J Pak Med Assoc. 2020;70:202-207.

20. Akturk S, Buyukavci R, Aslan O, Ersoy Y. Comparison of splinting and Kinesio taping in the treatment of carpal tunnel syndrome: a prospective randomized study. Clin Rheumatol. 2018;37:2465-9. 